Témoigner Témoigner. Entre histoire et mémoire

Getuigen Revue pluridisciplinaire de la Fondation Auschwitz

$117 \mid 2014$

Amis ? Ennemis ? Relations entre mémoires

\title{
Rwanda 94. Une tentative de réparation symbolique envers les morts
}

Rwanda 94. Een poging tot symbolisch herstel

Rwanda 94. Searching for a symbolic reparation

Daniel Weyssow

\section{(2) OpenEdition}

Journals

\section{Édition électronique}

URL : http://journals.openedition.org/temoigner/1196

DOI : $10.4000 /$ temoigner. 1196

ISSN : 2506-6390

Éditeur :

Éditions du Centre d'études et de documentation Mémoire d'Auschwitz, Éditions Kimé

Édition imprimée

Date de publication : 1 mars 2014

Pagination : 15

ISBN : 978-2-84174-663-7

ISSN : 2031-4183

Référence électronique

Daniel Weyssow, «Rwanda 94. Une tentative de réparation symbolique envers les morts », Témoigner. Entre histoire et mémoire [En ligne], 117 | 2014, mis en ligne le 01 juin 2015, consulté le 23 octobre 2020. URL : http://journals.openedition.org/temoigner/1196; DOI : https://doi.org/10.4000/temoigner. 1196

Ce document a été généré automatiquement le 23 octobre 2020.

Tous droits réservés 


\title{
Rwanda 94. Une tentative de réparation symbolique envers les morts
}

\author{
Rwanda 94. Een poging tot symbolisch herstel \\ Rwanda 94. Searching for a symbolic reparation
}

Daniel Weyssow

1 Il faut, de toute évidence, remercier le Groupov de s'être investi corps et âme dans la création de ce remarquable spectacle qui participe pleinement à et de la mémoire du génocide. Vingt ans plus tard, le collectif reste - comment pourrait-il s'en extraire ?sous l'influence de l'événement. Le film Rwanda 94 procède de l'enregistrement du spectacle donné en 2000 au Théâtre de la Place à Liège. Ceux qui ont eu la chance d'assister à l'une des représentations de la tournée du spectacle (1999-2005) se souviendront avec solennité des moments éprouvés. Les autres en découvriront ici, avec satisfaction, toutes les facettes et, plans rapprochés aidant, même davantage, sans rien perdre de l'importance de la représentation d'origine. Rwanda 94 est un événement théâtral intégrant " témoignages, conférence, chœurs parlés et chantés, compositions musicales, projections d'images, reportage, fiction théâtrale, avec acteurs, masques et marionnettes. » Une œuvre qui tente de concilier "vérité » et reconstitution par l'histoire, le témoignage et la réflexion. À l'ombre du génocide qui emporta près d'un million de personnes, la genèse du processus, les imbrications historiques et sociales ainsi que les responsabilités y ayant mené sont exposées et analysées.

2 Le Groupov, qui a pour démarche de « réfléchir à ce qui nourrit notre quotidien, à ce qui nous détermine socialement, culturellement, historiquement ", éprouve depuis ses origines en 1980 un certain sentiment d'urgence. Comment en effet comprendre ce $\mathrm{XX}^{\mathrm{e}}$ siècle et ses génocides? Après ceux, reconnus, perpétrés contre les Arméniens et les Juifs, ce dernier étant par ailleurs rappelé dans le spectacle, était-il si étonnant d'en voir surgir un troisième ? Il eut lieu cette fois sous le regard à la fois placide et atterré de la communauté internationale qui, ONU en tête, pourtant prévenue du drame qui se préparait, ne fit rien pour le prévenir ou l'empêcher. Rwanda 94, comme son titre 
l'indique, est une "tentative de réparation symbolique envers les morts». Le spectacle convoque les spectres qui hantent les consciences et témoignent, aux côtés des survivants, des souffrances traversées. Il est aussi «à l'usage des vivants " parce qu'il reste, entre autres, à ouvrir les yeux. Ce génocide n'est pas sorti ex nihilo, il n'est pas un accident de l'histoire, mais une émanation de celle-ci, résultant de l'histoire du Rwanda et, ce faisant, de ses colonisations. Depuis 1959, de très nombreux pogroms l'ont précédé comme autant de prémisses. Puisse cette œuvre, puisque telle est sa raison d'être, contribuer à éveiller la vigilance et à prévenir. Pour le Rwanda, "Suisse de l'Afrique ", il est trop tard. Son horizon, aujourd'hui, se borne à ses collines gorgées de sang et aux cauchemars.

Plus d'infos:

Rwanda 94. Une tentative de réparation symbolique envers les morts, à l'usage des vivants, spectacle de Marie-France Collard, Jacques Delcuvellerie, Dorcy Rugamba, Yolande Mukagasana, Jean-Marie Piemme, Mathias Simons (655'). Film réalisé par Marie-France Collard et Patrick Czaplinski, Groupov et Parallèles Productions, coproduction de la RTBF-La Deux, 2013.

+ Euvres en chantier: Rwanda 94. Groupov 20 ans, de Marianne Sluszny \& Guy Lejeune, $\left(52^{\prime}\right)$;

Rwanda. À travers nous, l'humanité, de Marie-France Collard, (155');

et Bruxelles-Kigali, de Marie-France Collard, (118').

\section{RÉSUMÉS}

Coffret DVD Le film Rwanda 94, enregistrement du spectacle donné en 2000 au Théâtre de la Place à Liège par le Groupov, vient de paraître dans un coffret proposant trois documentaires supplémentaires essentiels pour appréhender le travail du collectif lors de la conception du spectacle et autour de sa réception à Kigali.

DVD box: The film Rwanda 94 is a recording of the eponymous play that was staged in 2000 by Groupov at the Théâtre de la Place in Liège, Belgium. The box contains three extra documentaries on the preparatory work and the play's reception in Kigali.

DVD-box: De film Rwanda 94 is een opname van het gelijknamige toneelstuk dat in 2000 door Groupov werd opgevoerd in het Théâtre de la Place in Luik. De box bevat drie extra documentaires die inzicht bieden in het voorbereidende werk tijdens de productie, en de ontvangst in Kigali. 